\title{
Augmenting the Out of Classroom Learning Of Machine Drawing Laboratory Course
}

\author{
Shreeshail M. L. ${ }^{1}$, C. M. Koti ${ }^{2}$ \\ 1,2 Department of Mechanical Engineering, \\ B.V. Bhoomaraddi College of Engineering and Technology, \\ Hubli, Karnataka-580031, India. \\ ${ }^{1}$ shreeshailmlmech@yahoo.com,shreeshail_m@bvb.edu \\ ${ }^{2}$ cmkoti@bvb.edu
}

\begin{abstract}
Engineering drawing, traditionally termed as engineering graphics, has been the language of engineers. When it comes to mechanical engineering, this language gets elevated to a level fetching its status of first language in its domain. In engineering practices, any lapse in reading/interpreting drawings will be costly. The error in reading engineering drawings has been a worrying factor in the industries for engineering practitioners. There is a need for an immediate focus on the teaching-learning activity in this drawing course. This article reports an attempt to elevate the graphical communication skills in a class of $2^{\text {nd }}$ year mechanical engineering students. The purpose of the study was to test the effectiveness of the 'out of classroom' approach in improving the skill. The results show that the teaching approach is capable of enhancing the engineering drawing skills, and the approach has the potential to elevate the skill in one semester course of study. In the middle of our study, we attempted two more practices which are worth sharing. First practice was letting student recognize his/her own skill-level on the first class of the course and the skill-level achieved on the last class of the course and the second, psychological effect of quiz in assessing the learnt skills.
\end{abstract}

Keywords: Graphical communication skills, engineering drawing, out of classroom approach.

\section{Shreeshail M. L.}

Department of Mechanical Engineering,

B.V. Bhoomaraddi College of Engineering and Technology, Hubli, Karnataka-580031, India.

${ }^{1}$ shreeshailmlmech@yahoo.com,shreeshail_m@bvb.edu

\section{Introduction}

The expectations of people have increased to improve the quality of lifestyle we live today and to make it look simpler also.

There is no doubt in the contribution of engineering and its applications which not just supports our today's living but also transform our lives. Prior to the evolution of various systems of spoken and written languages, drawing was the only reliable means of communication between the people (N. Sidheswar et al., 2012). The importance of drawing and its communication capabilities has raised many eyebrows. Even at the Secondary School level, the Malaysian School System has successfully included Technical or Engineering Drawing in their integrated curriculum since 1994 (Lilia et al., 2012, and Kementerian, 2004). This kind of early exposure to the technical course indicates the importance of preparing a student potential enough to read and understand the language, i.e. Engineering Drawing.

Machine Drawing is an essential tool for anyone who expects to work in an industry or to become a professional mechanical engineer. Preparing accurate drawing is as important as the ability to read drawings correctly.

To learn to read the drawings, the best way is to learn to prepare them. Through the Machine drawing laboratory course, we can impart the drawing skills and try to minimise the gap in skill level.

In this paper, we will be discussing the experience gained while performing 'out of classroom' activity. We initially targeted to achieve 3 specific program outcome elements (indicators) namely; to demonstrate the ability to do the measurements (b2C), to generate a detailed drawing (c2B) and ability to create computer models and technical drawings (g1C).

Students were conventionally learning drawing courses from different sources like assigned reference text books, scheduled course plans, more or less converting printed textbook sheets to drawing sheets. 
After teaching the students the basics of machine drawing, this 'out of classroom' activity has been introduced. This activity was named as 'Key-Lock' activity.

In designing of this out of classroom activity (Dave $@$ @url), following aspects have been considered -

- Activity must be simple and creative.

- Activity should be appropriate, inclining to course content.

- Activity should be pedagogically sound, making sense from students' learning point.

The formation of student teams, working out with all their team members in measuring the profiles of key and lock, interpreting the measurements in their detailed drawings and finally getting approved by their team leader gave the sense of responsibility not just to a student team member but also to the team leader (Creative Education Blog@url). The outcome of this innovative out of classroom pedagogic activity has been more satisfying in attempting the targeted performance indicators.

\section{Observations and Discussions}

\section{A. Key-Lock Activity}

Students were asked to form 15 teams. Each team consisted five students, including one team leader. Prerequisites made for this course was that the student should know about the engineering drawing, since the class had diploma-entry students also. Then, fifteen team leaders were supposed to approach the faculty with all their team members, one team at a time. And the most important, teams must approach only in their free time, purposefully avoiding this meeting with faculty inside classroom. This helps students to feel more responsive when they are in 5-students team when compared to 75-students class. The students were asked to carryout this activity in either machine-shop or in metrology laboratory. Few students worked in these two laboratories, few worked outside as there were no restrictions.

Instructions were given to the team members, especially to the team leader who was supposed to take care of all the teamwork. Each team must have one key, one lock, two callipers and drawing instruments. Each team was undergoing the detailed explanation on how to measure different profiles of the working area of the key and how to measure only the outline working profile of the lock (enlarged view shown in Fig. 1).

A rough sketch of key profile and lock were asked to be drawn first, which was not to scale. Then, students were taught to make use of vernier calipers to its full extent to measure the profiles and take down the readings in the rough sketch. By this, they will be having all lines or profiles annotated in the rough sketch. The task ahead was to create a detailed drawing of both key and lock as shown in Fig. 2 and Fig. 3.

On regular basis, students were consulting the faculty for various queries in these drawings. Special care was taken on how to improve these detailed drawings. Students not just came with drawing queries, but also they had many issues related to manufacturing and fabrication.

Even various sectioned views were included to know the exact cross-sections (Fig. 2 and Fig. 3). Once this detailed drawing was finished from a student member end, he/she had to submit that to his/her team leader for approval process. Now, the team leader would not just check the drawings but also focus on the flawless communication capability of that key and lock parts through these drawings. After the team leader has approved that drawing, then that team leader should take care in submitting all his team member's drawings for final submission to the faculty for the assessment process.

The rubric for the assessment of this activity is highlighted in table 1 and table 2 . Table 3 shows the details of continuous internal evaluation of four students.

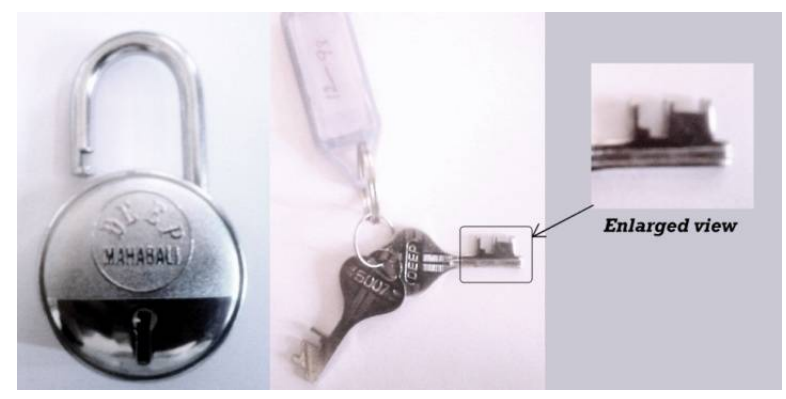

Figure 1: Pictorial view of the Key and Lock with enlarged view of working profile.

Table 1 : Details of Evaluation.

\begin{tabular}{|c|c|c|}
\hline \multirow{2}{*}{$\begin{array}{c}\text { Continuous Internal } \\
\text { Evaluation } \\
(80 \%)\end{array}$} & $\underline{\text { Assessment }}$ & $\frac{\text { Weightage in }}{\text { Marks }}$ \\
\cline { 2 - 3 } & $\begin{array}{c}\text { Int. Assessment }-1,2 \\
\text { and Attendance }\end{array}$ & 65 \\
\cline { 2 - 3 } & $\begin{array}{c}\text { Class work + } \\
\text { Assignment }\end{array}$ & $\mathbf{1 5}$ \\
\hline $\begin{array}{c}\text { Semester End } \\
\text { Examination (20\%) }\end{array}$ & 20 \\
\hline \multicolumn{2}{|c|}{ Total } & 100 \\
\hline
\end{tabular}

Table 2 : Details of Key-Lock activity assessment.

\begin{tabular}{|l|c|l|}
\hline Detailed Drawing & Marks & $\begin{array}{l}\text { Details (applies to } \\
\text { both parts) }\end{array}$ \\
\hline Key & 05 & $\begin{array}{l}\text { Measurement } \\
\text { accuracy }-01 . \\
\text { Drawing orthogonal } \\
\text { views with } \\
\text { annotations }-03 . \\
\text { Sectioned view }-01 .\end{array}$ \\
\hline Total & 05 & 10 (reduced to 5 marks) \\
\hline
\end{tabular}




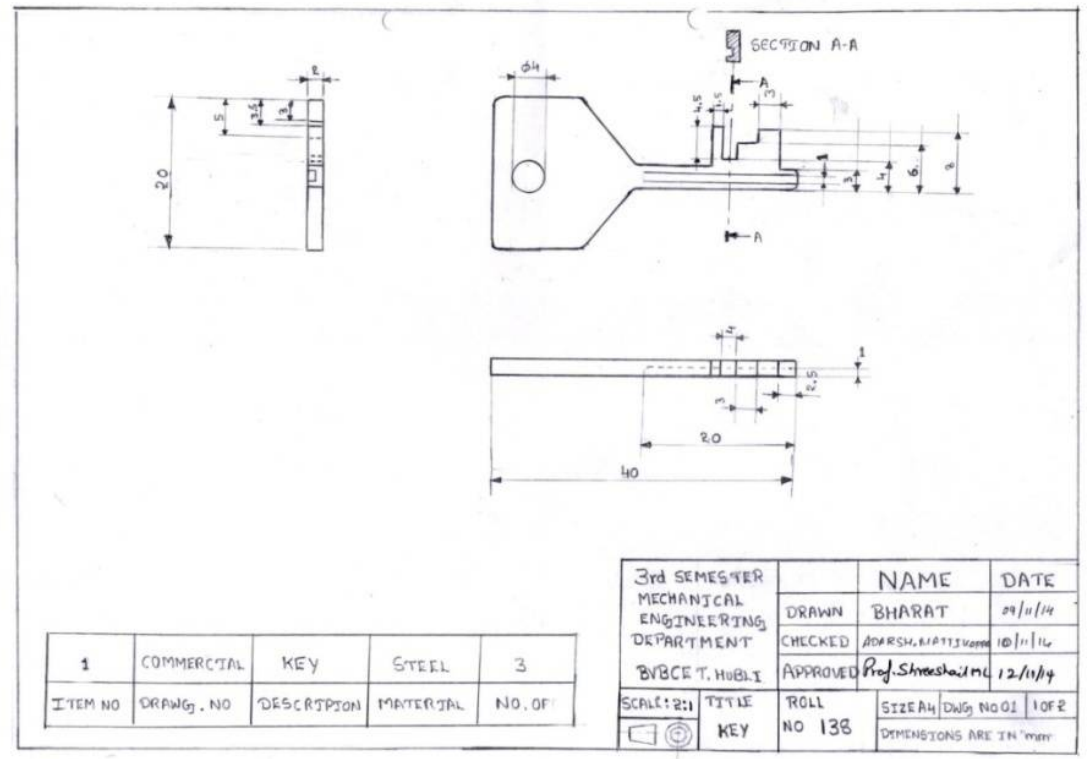

Figure 2: Scanned view - Detailed drawing of the Key with sectioned view of working profile.

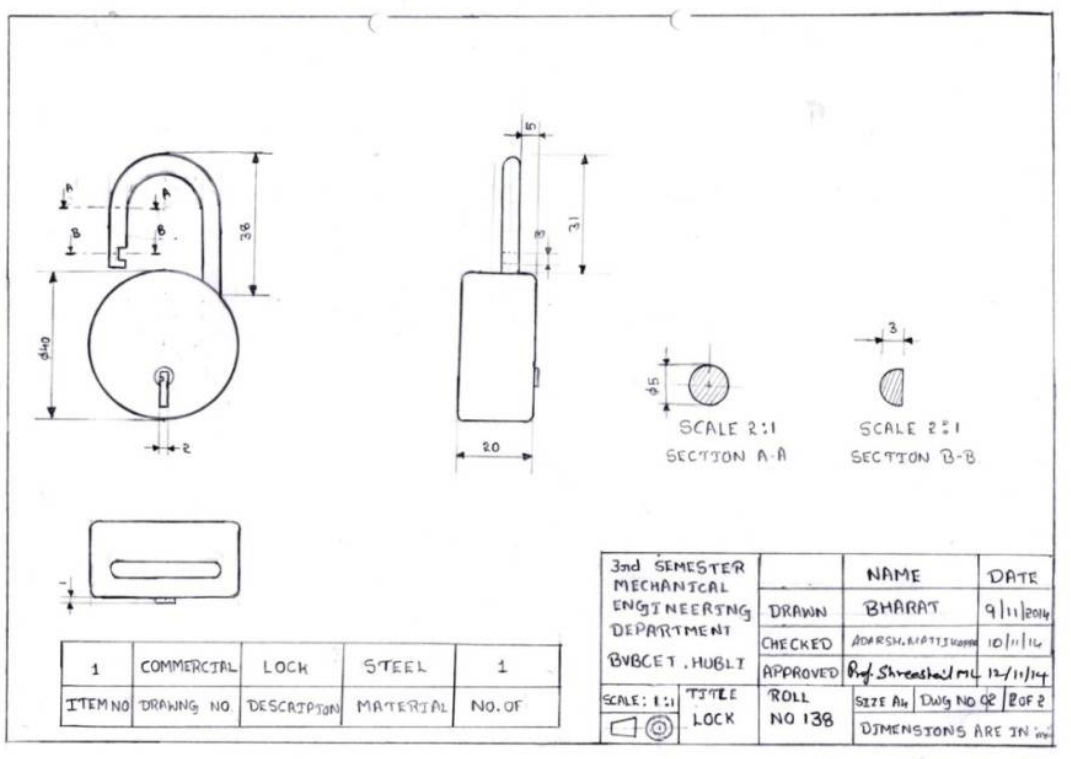

Figure 3: Scanned view - Detailed drawing of the Lock with sectioned view of working profile.

Table 3 : Details of Continuous Internal Evaluation of four students.

\begin{tabular}{|c|c|c|c|c|c|c|}
\hline \multirow{2}{*}{$\begin{array}{c}\text { Student } \\
\text { Roll no. }\end{array}$} & \multirow{2}{*}{$\begin{array}{c}\text { Int. Assessment 1 } \\
(\mathbf{3 0})\end{array}$} & \multirow{2}{*}{$\begin{array}{c}\text { Int. Assessment 2 } \\
\mathbf{( 3 0 )}\end{array}$} & $\begin{array}{c}\text { Attendance } \\
(\mathbf{0 5})\end{array}$ & \multicolumn{2}{|c|}{ Class work (15) } & \multirow{2}{*}{$\begin{array}{c}\text { Tssignment } \\
(\mathbf{1 0})\end{array}$} \\
\hline 93 & 21 & 21 & 05 & 08 & 05 & 60 \\
\hline 132 & 17 & 18 & 05 & 08 & 05 & 53 \\
\hline 138 & 24 & 29 & 05 & 08 & 05 & 71 \\
\hline 145 & 20 & 26 & 05 & 10 & 05 & 66 \\
\hline
\end{tabular}




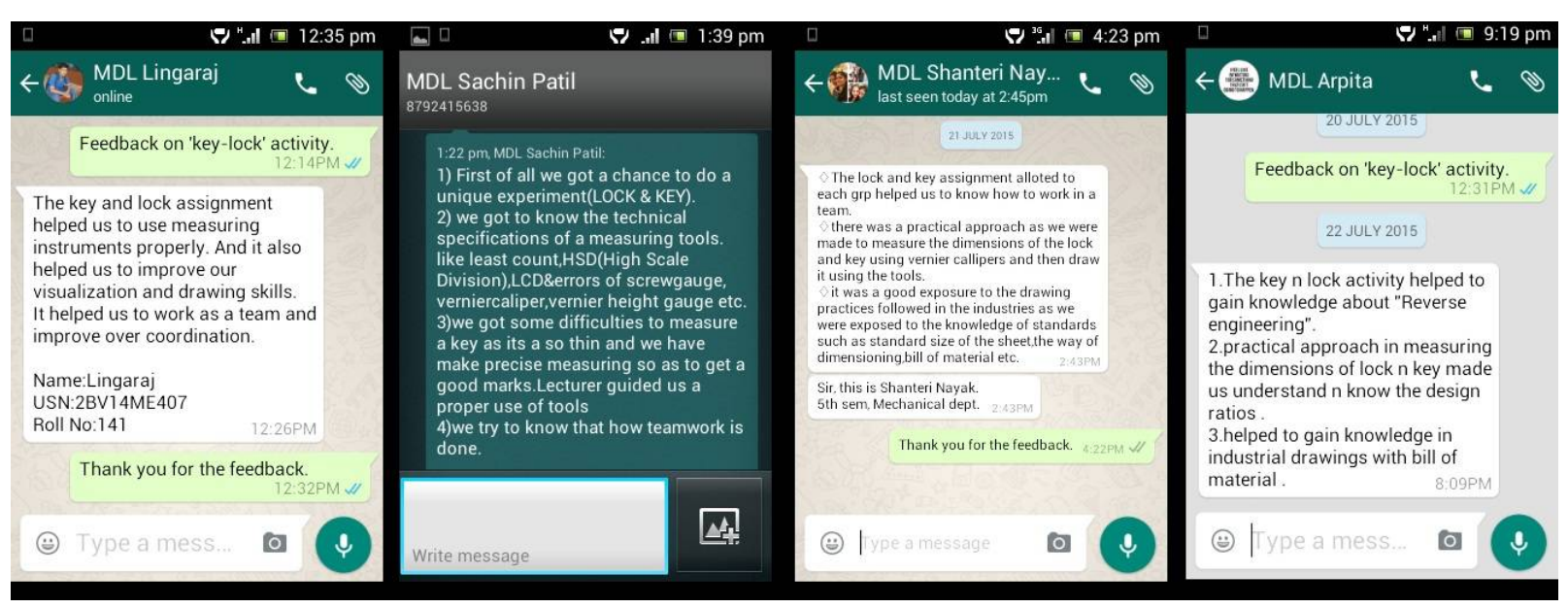

Name: J. Shubhashre
Roul No: 1106
Div : $K$

B.pou
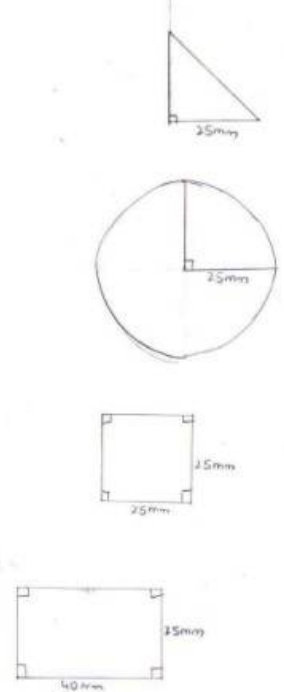

Figure 4: Screenshots of the student's feedback on key-lock activity.

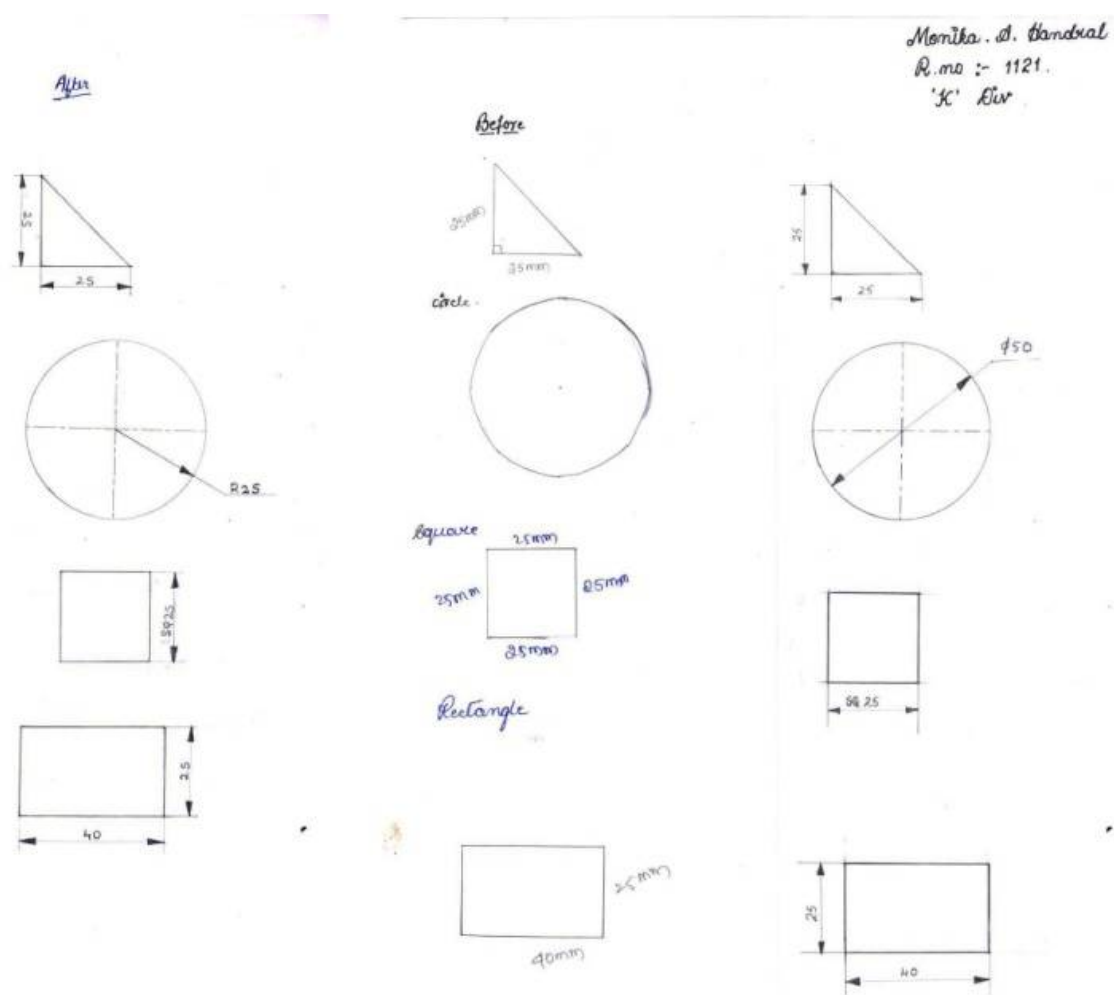

Figure 5 : Scanned view - Before / after activity.

The out of classroom activity addressed 3 specific program outcome elements (indicators) namely; to demonstrate the ability to do the measurements (b2C), to generate a detailed drawing (c2B) and ability to create computer models and technical drawings (g1C). In addition to this, few more pedagogical issues were taken care of -

- Facilitated active learning.

- Enhanced and correlated different learning styles, visual and active learning.

- Ability to work in a team, to build learning community.

- $\quad$ Ability to build skills.

Students responded positively for this kind of unique activity. Feedbacks were also taken from the students to know how this activity helped them to improve teachinglearning process. Some of the screenshots of the feedback are shown in the figure 4.

B. Two new practices- 'Before to After' activity and Quiz.

After the course completion, the best way to make a student realise his/her learnt skill is to know the two levels. This is achieved through a simple, unique activity, named as 'Before to after' activity. Here the student is asked to sketch few standard geometric shapes on the first day of the course delivery on one half side of the drawing sheet. Then after course completion, students are given back those sheets and asked them to sketch the same 
standard shapes on the second half of the drawing sheet. The clear cut differences shows the drawing skill level the student has achieved. The scanned view of "before to after" activity is shown in figure 5 .

Students skill levels were examined through a second activity, i.e. quiz. Both offline and online (moodle) quiz were conducted. In first quiz, 10 set of questions were asked to answer in fill up the blank or descriptive mode of answering. The same set of questions were asked in second quiz for different students, but they had to answer one from four choices i.e. answering in objective mode. The result analysis showed, students answering in descriptive mode involve themselves to answer while in objective mode, they were puzzled and performed low. In the objective mode quiz, all 10 questions" answer were option 'd' i.e. none of the above. This was the reason behind the students' less involvement in answering all 10 questions with ' $d$ ' none of the above option. The performance details in both quiz are given in table 4 . The outcome of these two practises conveys that the student has learnt the skills but while adopting and practising the same, student showed less involvement.

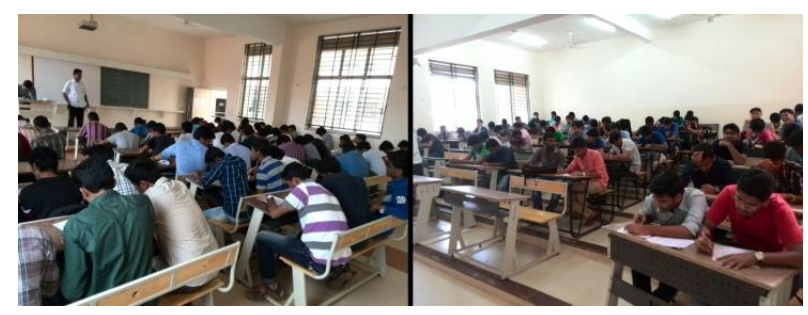

Figure 6 : Students undergoing individual quiz activity.

Table 4 : Details of overall performance of both Offline and Online/Moodle quiz.

\begin{tabular}{|l|c|}
\hline \multicolumn{1}{|c|}{ Quiz type } & $\begin{array}{c}\text { Overall average } \\
\text { (out of 10 marks) }\end{array}$ \\
\hline Offline & 6.68 \\
\hline Moodle/Online & 2.18 \\
\hline
\end{tabular}

\section{Conclusions}

This investigation shows better involvement of both faculty and students in teaching-learning process due to the inclusion of 'out of classroom" activity in any technical course. This activity enhances creativity, imagination, skill and will have more lasting impact than a classroom lecture. This activity helps the student to overcome behaviour problems, to feel engaged and motivated to the course. This also results in improved attendance.

\section{Acknowledgement}

The authors would like to thank Dr. Ashok S. Shettar, Vice - Chancellor, KLE Technological University and Dr P. G. Tewari, Principal, B.V. Bhoomaraddi College of Engineering and Technology for the encouragement. We would like to thank Dr B.B. Kotturshettar, Head of
Department, Mechanical Engineering, B.V. Bhoomaraddi College of Engineering and Technology for their encouragement and support. We also like to thank technical staffs of Mechanical engineering department for their support.

\section{References}

1. N. Sidheswar, P. Kannaiah, V.V.S. Sastry, (2012) Machine Drawing, 45 ${ }^{\text {th }}$ edition, Tata McGraw-Hill, 3-5.

2. Lilia Halim, Ruhizan M. Yasin , \& Azaman Ishar, (February 2012) CAMED: An Innovative Communication Tool In Teaching Engineering Drawing , WSEAS Transactions On Information Science And Applications, Issue 2, Volume 9, 58-67.

3. Kementerian Pelajaran Malaysia. (2004). Integrated Secondary School Curriculum Syllabus for Engineering Drawing Form 4 and 5. Kuala Lumpur, KPM.

4. Dave Douglass, The Out-of-Classroom Experience, http://www.4faculty.org/includes/digdeeper/Outside/out side.htm

5. 10 Reasons to Take Learning Outside the Classroom, Creative Education Blog, http://www.creativeeducation.co.uk/blog/learningoutsid etheclassroom/ 